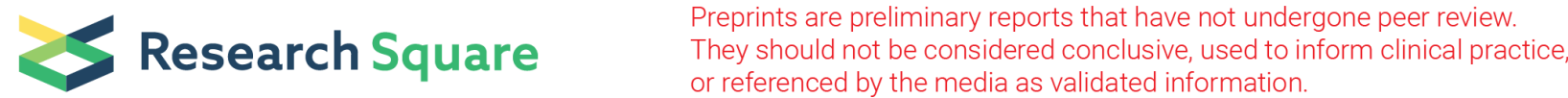

\section{Tracking Immunization Coverage, Dropout and Equity Gaps Among Children Aged 12-23 Months in Malawi. Bottleneck Analysis of the Malawi Demographic and Health Survey}

\section{Kondwani Mmanga}

African Field Epidemiology Network

Tisungane Edward Mwenyenkulu

Malawi University of Science and Technology

\section{Owen Nkoka}

University of Glasgow

Fentinesh Nibret Tiruneh

Bahir Dar University

Peter Austin Morton Ntenda ( $\nabla$ pntenda@mac.medcol.mw )

University of Malawi College of Medicine https://orcid.org/0000-0002-2548-3163

\section{Research}

Keywords: Immunization Coverage, Dropout rates, Equity gaps, under-five children, Bottleneck analysis, Malawi Posted Date: February 15th, 2021

DOI: https://doi.org/10.21203/rs.3.rs-198573/v1

License: () (1) This work is licensed under a Creative Commons Attribution 4.0 International License. Read Full License 


\section{Abstract}

Background: Immunization is considered an effective tool for controlling and eliminating life-threatening infectious diseases. However, most studies on immunization have mainly focused on vaccination coverage while data on dropouts and equity gaps is very scanty. Thus, the aim of the present study was to describe the trend in immunization coverage, dropout rates and effective immunization coverages (FVC) among children aged 12-23 months in Malawi.

Methods: We conducted secondary analyses of the cross-sectional data taken from three waves of the Demographic and Health Surveys (2004, 2010, and 2015-16). Using the bottleneck analysis, outputs were generated based on service coverage, demand/equity (service utilization) and quality/effective coverage. The World Health Organization benchmarks were used to assess gaps in the immunization coverage indicators.

Results: The coverage was above $90.0 \%$ in most of the antigens while full immunization status was estimated at $65 \%, 84 \%$, and $73 \%$ in 2004, 2010, and 2015 respectively. The highest coverage was observed in BCG and lowest in Oral Polio Vaccine1 (OPV1). OPV1 coverage was less than $90 \%$ in 2004 cohort year, whilst Penta3 and MCV1 coverages were less than $90 \%$ in 2004. Additionally, full vaccination coverage (FVC) was $65 \%, 84 \%$, and 74\% in 2004, 2010, and 2015 respectively. Dropout rates of Penta3 and MCV1 were significantly higher than $10 \%$ in 2004 however, the dropouts had U-shaped patterns. The logistic region analyses showed that children were significantly less likely to be immunized with Penta3 and MCV1 in all cohort years compared to Penta1.

Conclusions: Though immunization coverage was in line with the national and district targets for various antigens between 2004 and 2015, however, the FVC is still lagging behind. Furthermore, the dropout rates for Penta3 and MCV1 showed U-shaped patterns. Thus, health education, supervision, and orientation of service providers are instantly needed to address disparities that are existing in FVC.

\section{Background}

Immunization has demonstrated to be an effective means of controlling and eradicating life-threatening infectious diseases since the 20th century [1]. Every year, immunization is estimated to prevent about 23 million child deaths [2]. The global effort to use immunization as a public health intervention began when the World Health Organization (WHO) launched the Expanded Programme on Immunization (EPI) in 1974 where six vaccines (diphtheria, whooping cough, tetanus, measles, poliomyelitis, and tuberculosis) were recommended to be administered to young children aged 0-24 months through the routine infant immunization [3]. However, since then additional of new vaccines have now been effected to the original six recommended [4]. Even though immunization coverage has shown great improvements over the last two decades worldwide, unfortunately, the coverage has remained trapped at $86 \%$, and it has shown no substantial changes over the past years [5]. To benefit from the full direct and indirect effects of immunization, the WHO came up with the Global Vaccine Action Plan (GVAP) which demand on countries to achieve $90 \%$ coverage for all antigens at national level and at least $80 \%$ coverage in all antigens in $80 \%$ of districts by the year 2020 [6].

In 1979, the Malawi Expanded Programme on Immunization (EPI) was officially launched and began to administer vaccines against the six diseases; a dose of BCG vaccine against tuberculosis (TB); three doses of DPT, against diphtheria, tetanus, and pertussis; at least three doses of oral polio vaccine (OPV) against polio; 
and one dose of measles-containing vaccine against measles [7]. However, it was reported that only smallpox vaccinations were administered on a large scale while antigens such as Bacillus Calmette-Guerin (BCG) and diphtheria, tetanus, and pertussis (DPT) were delivered in a few health facilities in Malawi the beginning of 1970s [8]. In the year 2012, the Malawi government substituted the DPT vaccine with a pentavalent vaccine that protects against DPT, hepatitis B (HepB), and Haemophilus influenza type b (Hib) - DPT-HepB-Hib in its EPI [9]. Additionally, in November 2011 and October 2012, the Government of Malawi further introduced new vaccines namely; the pneumococcal conjugate vaccine (PCV13) against bacterial pneumonia and monovalent human rotavirus vaccine (RV1) against severe diarrhea caused by rotavirus into its EPI, respectively [10]. In 2015, the Malawi government introduced measles second dose, whilst in 2016 the tOPV dose was switched to bOPV. Similarly, the Tetanus Toxoid vaccine was switched to Td, PCV 131 does to 4 doses viral and the Measles Rubella vaccine was introduced. Additionally, in 2018/2019 the Malawi EPI planned to switch bOPV to IPV and Human Papilloma Vaccine (HPV) has just been introduced [11]. Figure 1 shows the number of antigens introduced in Malawi's EPI schedule from 1979 to 2019.

The Malawian EPI recommends that the BCG and polio 0 vaccines should be given at birth or within the first 14 days after birth, the pentavalent (Penta), pneumococcal (PCV), rotavirus (Rota) and oral polio vaccines (OPV) should be given at approximately 6,10 , and 14 weeks of age. The measles vaccine (MCV) is recommended to be administered as soon as the child reaches 9 months of age [12]. Additionally, Tetanus Toxoid (TT) vaccine is scheduled to be provided to pregnant women and women of child-bearing age (15-45 years and pregnant women) at first contact. Table 1 presents the EPI schedule followed in Malawi. Obstacles to reaching every child with the full complement of vaccines have been identified in some settings. These factors included maternal education, distance to facilities, inadequate vaccines, poorly trained and motivated human resources and poor quality of services [13]. Studies from Malawi on vaccination, have reported that women's low education, having one or none antenatal visits, having no immunization card, having immunization card but not seen, residing in poor households, having children of high birth order, and living in central region were the most significant factors associated with decreased odds of achieving vaccination coverage and complete vaccination [8][14]. Furthermore, other studies have cited that vaccine stock-outs at health facility level are the reasons for no vaccination [15]. Most of these studies have mainly focused on whether the child has received full-vaccination, under-, non-vaccination, and vaccination coverage. 
Table 1

Schedule of the Malawi's Expanded Programme on Immunization

\begin{tabular}{|ll|}
\hline Age & Vaccine \\
\hline At birth or first contact & BCG \\
\hline At birth up to 2 weeks & OPV 0 \\
\hline At 6 weeks & OPV1 and Pentavalent1 and PCV1, RV1 \\
\hline At 10 weeks & OPV2 and Pentavalent2 and PCV2, RV2 \\
\hline At 14 weeks & OPV3 and Pentavalent3 and PCV3 \\
\hline At 9 months & Measles \\
\hline $\begin{array}{l}\text { Pentavalent includes DPT, HepB, and Hib, BCG, bacillus Calmette-Guérin; OPV, oral polio vaccine; DPT, } \\
\text { diphtheria, pertussis, tetanus; HepB, Hepatitis B; Hib, Hemophilus influenza type b; PCV, Pneumococcal } \\
\text { conjugate vaccine, RV, Human rotavirus vaccine. }\end{array}$ \\
\hline
\end{tabular}

Worldwide, about $85 \%$ of infants (116 million infants) received DTP3 and one dose of MCV by the end of 2019, thus, protecting them against infectious diseases that can cause serious illness and disability. Meanwhile, 123 countries were reported to have reached at least $90 \%$ coverage of DTP3 vaccine [2]. Similarly, the EPI in Malawi has managed to sustain a high coverage of immunization above $80 \%$ of various antigens for several years. However, recently there has been a significant decline in fully immunized children from $81 \%$ in 2010 to $76 \%$ [10]. In Malawi, routine data on immunization is collected using two national routine administrative tools namely official WHO/UNICEF Joint Reporting Form (JRF) and District Vaccination Data Management Tool (DVDMT). Unfortunately, due to data quality issues, these databases usually report inconsistent coverage, abnormally high as well as high dropout rates. Even though, the routine reports provide information on immunization coverage; however, information may be inaccurate and misleading. The data quality plays a fundamental role in the success or failure of an immunization programme and poor quality immunization data threatens to undermine national and international investments [16].

Usually, in Malawi, the national wide survey focuses mainly on immunization coverage and completeness of immunization. However, immunization dropouts are not reported. The dropout rate is of great essence, as it indicates whether there is an access problem for the parents, i.e. whether they have difficulty in getting to the immunization services for subsequent doses or whether there is a problem for parents in utilizing the health services [17]. Therefore, coverage surveys can validate routine reports and provide additional information on immunization and identify strategies to improve immunization activities. Accordingly, we aimed to describe the trend in immunization coverage, dropout, equity gaps, and effective immunization coverages (FVC) among children aged 12-23 months in Malawi.

\section{Methods}

Study setting

The small nation of Malawi is part of the sub-Sahara of Africa and is a landlocked country located in the southeastern part of the continent. It is bordered to the north and northeast by the United Republic of Tanzania; 
to the east, south, and southwest by the People's Republic of Mozambique; and to the west and northwest by the Republic of Zambia [18][19][20]. Malawi is one of the poorest countries in the world with GNI per capita of US $\$ 320$ and about $85 \%$ of the population live in rural areas [21]. The economy of Malawi is based primarily on agriculture, which accounts for 30 percent of the gross domestic product (GDP) [22]. Health care services in Malawi are provided through both the public and the private sectors [23]. The public sector includes all facilities under the Ministry of Health (MoH), Ministry of Local Government and Rural Development, the Ministry of Forestry, the Police, the Prisons and the Army. The private sector consists of private for-profit and private not for profit providers mainly Christian Association of Malawi (CHAM) [11][23]. The public sector provides services free of charge while the private sector charges user fees for its services. There are currently 977 health facilities in Malawi comprising 113 hospitals, 466 health Centres, 48 dispensaries, 327 clinics, and 23 health posts. These health facilities are managed by the government (472), CHAM (163), Private (214) and Non-government Organizations (NGOs) (58) and company (69) [5]. All these forms of institutions provide immunization services in Malawi.

\section{Data sources}

The current study analyzed the data obtained from the Malawi Demographic and Health Survey (MDHS) 2004, 2010, and 2015-16. The methodology used in these surveys can be obtained in detail elsewhere [10][24][25]. In brief, the surveys employed a two-stage sampling designed to produce nationally representative samples. The surveys utilized sampling frames from the Malawi Population and Housing Census (MPHC) conducted in 1998 and 2008. The first stage selected 850,849 , and 522 clusters also known as standard enumeration areas (SEAs) proportional to population in 2015-16, 2010, and 2004 respectively. The second stage involved selection of $27,516,27,307$, and 15,041 households from the SEAs with an equal probability systematic selection in 2015-16, 2010 , and 2004 respectively.

\section{Data collection}

Using face-to-face interviews, data were collected on the demographic, social, and economic characteristic of the respondents and their households. Respondents were asked to show a health passport or any other document where (NAME)'s of vaccines were written down. If the respondents could not show a health or immunization card, they were then asked to recall any vaccinations ever received to prevent (NAME) from getting diseases, including vaccinations received in campaigns or immunization days or child health days. Particularly, respondents were asked to report whether the (NAME) received BCG, polio, pentavalent, rotavirus, pneumococcal and measles vaccines. As regards polio, pentavalent, rotavirus, and pneumococcal vaccines, respondents were further asked to report a number of times the (NAME) received each specific vaccine [10][24] [25]. Of the selected households, 11,698 in 2004, 23,020 in 2010 and 24,562 in 2015, women were interviewed representing $97.7 \%, 96.9 \%$, and $95.7 \%$ respectively. As recommended by the WHO [10], the present study included children aged 12-23 months. Thus, the final samples analyzed were $2,211,3,741$, and 3,225 children in 2004,2010 , and 2015-16 respectively.

\section{Inclusion criteria}

All live children aged 12-23 months prior to each survey, living with their guardians and had information on immunization were included in this study. 


\section{Bottle neck analysis}

Bottleneck analysis (BNA) is an approach based on Monitoring of Results for Equity System (MoRES) for planning equity-focused interventions and identifying bottlenecks in their uptake [26]. The MoRES was developed in 2010 as part of UNICEF's refocus on equity to ensure that UNICEF is as effective as possible in the protection and promotion of children's rights [27]. The BNA framework is premised on the notion that effective coverage of services is influenced by four main domains namely: supply, demand, quality, and environment. (1) Supply determinants of services are predominantly controlled by the health care delivery system and have three important components: commodities, human resources, and geographic access. (2) Demand determinants of services are predominantly controlled by the community, and have two important components known as initial utilization and continuous utilization of services (3) Quality determinants of services are predominantly controlled by the health care delivery system and relate to the services being able to meet the quality standards set within national guidelines [13]. However, in this study, we focused on the demand and quality determinants of services since the DHS does not have data on supply demands.

Variables and operational definitions

Immunization coverage

Immunization coverage is the proportion of children aged 12-23 month who received the recommended EPI vaccine antigens compared to the total number of infants who survived in the given target population. The immunization coverage rate is measured by comparing the number of antigens actually administered versus the total number of infants who survived in the given target population.

Partially immunized

Partially immunized children is defined as any child aged 12-23 months who missed some of the scheduled prescribed vaccines antigens considered to protect them against vaccine-preventable diseases.

\section{Unimmunized}

Unimmunized children are children who have not defaulted any of the scheduled EPI vaccinations. Usually unimmunized children is considered to be those aged 12-23 months and have not received DTP3.

Dropout rate

The dropout rate is calculated by comparing the number of infants who initiate the vaccination schedule against those that complete it and usually two domains are habitually used to calculate the dropout rate. These measures are the Penta vaccine and MCV1. Specifically, the dropout rate can be calculated subtracting children who received Penta1 from those who received Penta3 then divide by those who received Penta1 (Penta1Penta3) $\div$ Penta1 $\times 100 \%$ ). Also it can be can be calculated between the children who received Penta 1 and MCV1 divide by those who received Penta1 (Penta1-measles) $\div$ Penta1 x 100\%). The WHO recommends that the coverage of both the Penta1 to Penta3 and that of Penta1 to MCV1dropout rates should be less than $10 \%$ so as to have the better-quality of immunization coverage as well as to have the reduced rates under-five morbidity and mortality [28][29]. It should be taken into consideration that the dropout rate of more than $10 \%$ reflect underutilization of immunization services. 
Initial Utilization

An initial utilization of an immunization program is define as the proportion of children who received Penta1 vaccine during the past year in region/district. The numerator for this indicator is the number of children aged 12-23 months who received either BCG or Penta1 vaccine while the denominator is the number of children under 12-23 months eligible for Pentavalent 1 vaccination.

Continuous Utilization

The continuous utilization of an immunization program is defined as the proportion of children who received Penta3 vaccine during the past year in region/district. This indicator uses the number of children received Penta 3 vaccine as it numerator and the number of children under 12-23 months eligible for Penta 3 vaccination the denominator.

Adequate coverage

Adequate immunization coverage is defined as the percentage of children aged 12-23 months who were immunized with MR1 during the past year in region/district. The indicator is calculated by diving the number of children received MR1 vaccine by the number of children under 12-23 months eligible for MR1 vaccination.

Fully immunized coverage (FIC)

The FIC is defined children aged 12-23 months who BCG, OPV3, Penta3, PCV3, Rota2 and MCV1 vaccines. The number of children fully vaccinated by $12-23$ months according to the vaccination calendar timeline is considered as the numerator and the number of children under 12 eligible for full vaccination as the denominator.

Control variables

The control variables used in the present study included the year in which the survey was carried out and geographical region. In order to establish a trend in immunization coverage a 15 years period was sampled, the years included 2004, 2010, and 2015-16. The geographical region included northern, central, and southern and was used a proxy for administrative divisions in Malawi. The geographical region was chosen so as to establish the most underperforming area, thus for better policy implications.

Statistical analysis

Data were analyzed using SAS software version 9.4 (SAS Institute Inc., Cary, NC, USA) and Stata version 15 (Stata Corp, College Station, TX, USA). All analyses were performed separately for 2004, 2010, and 2015-16. Data were presented as frequency and percentages, and where necessary data was presented in the form of charts. Using Pearson's $\chi^{2}$, the bivariate analysis was performed to test the differences in distribution between groups (Penta1 vs Penta3, Penta1 vs MCV1, initial utilization [yes/no,], continued utilization [yes/no], adequate coverage [yes/no) and FVC [yes/no]). The univariate analyses were conducted using binary logistic regression to examine the magnitude of unimmunized with Penta3 and MCV1. The results of the univariate logistic regression were presented as the odds ratio (OR) with their corresponding $95 \% \mathrm{Cl}$. The statistical significance was considered when $p$-values were $<0.05$. 
The protocols for 2004, 2010, and 2015-16 MDHS were reviewed and approved by the Malawi National Health Sciences Research Committee (NHSRC), the Institutional Review Board of International Classification Function (ICF) Macro, and the Centers for Disease Control (CDC) in Atlanta. Data collection was implemented by the National Statistics Office (NSO). At the beginning of each interview informed consent was obtained from the participants. The authors sought permission from the DHS program for the use of the data. The data obtained from respondents were anonymous as names not written down thus ethics approval for this study was not required.

\section{Results}

Immunization coverage

Immunization coverages for various antigens are presented in Fig. 2. In all the three cohort years, immunization coverage was the highest for BCG antigens (92\% in 2004, 98\% in 2010, and 98\% in 2015) and the lowest in OPV antigens (80\% in 2004, 89\% in 2010, and 83\% in 2015). The coverages of Penta3 and MCV1 were less than $90 \%$ in 2004. The other vaccination coverages were 92\% for Penta3 in 2010 and 93\% for Penta3 in 2015.

Furthermore, the coverages for PCV3 and Rota2 in 2015 were $90 \%$ and $92 \%$ respectively. Whilst the coverage for MCV1 antigen in 2010 and 2015 were $93 \%$ and 91\% respectively.

Penta3 and MCV1 unimmunized children

Figure 3 shows unimmunized children with Penta3 and MCV1 between 2004 and 2015. The highest numbers of unimmunized children were observed in the year 2004 and lowest in the year 2010. As seen in the figure, 264 children and 347 children unimmunized with Penta3 and MCV1 in 2004 respectively. Additionally, 140 children and 201 children unimmunized with Penta3 and MCV1 in 2015 respectively.

Penta3 and MCV1 dropout rates.

Tables 2 and 3 dropout rates for Penta3 and MCV1. The Dropout rates for both antigens were significantly higher than 10\% in 2004 but with a U-shaped. In 2004 Penta3 dropout was 12.6\%. In 2010, the dropout rate significantly dropped to $3.4 \%$ and 2015-16 the dropout rate slightly increased. Similarly, In 2004 MCV1 dropout was $16.5 \%$, however, the dropout rate significantly dropped to about 5\% in 2010 and slightly increased in 201516. The dropout rates in 2004 were higher than the $10.0 \%$ cutoff point by World Health Organization. 
Table 2

Dropout rate in immunization coverage using DPT1/Penta1and DPT3/Penta3.

\begin{tabular}{|c|c|c|c|c|c|c|}
\hline Year & $\begin{array}{l}\text { Infants vaccinated } \\
\text { (Penta1) }\end{array}$ & $\begin{array}{l}\text { Infants vaccinated } \\
\text { (Penta3 }\end{array}$ & $\begin{array}{l}\text { Difference (Penta1- } \\
\text { Penta3) }\end{array}$ & $\begin{array}{l}\text { Dropout } \\
\text { rate }\end{array}$ & $\begin{array}{l}\text { Dropout } \\
\%\end{array}$ & $\begin{array}{l}P \\
\text { value }\end{array}$ \\
\hline 2004 & 2101 & 1837 & 264 & 0.125654 & 12.6 & $\begin{array}{l}< \\
0.001\end{array}$ \\
\hline 2010 & 3712 & 3585 & 127 & 0.034213 & 3.4 & $\begin{array}{l}<.001 \\
0.00\end{array}$ \\
\hline $\begin{array}{l}2015- \\
16\end{array}$ & 3134 & 2994 & 140 & 0.044671 & 4.5 & $\begin{array}{l}< \\
0.001\end{array}$ \\
\hline
\end{tabular}

Table 3

Dropout rate in immunization coverage using DPT1/Penta1and MCV1/MR1

\begin{tabular}{|c|c|c|c|c|c|c|}
\hline Year & $\begin{array}{l}\text { Infants vaccinated } \\
\text { (Penta1) }\end{array}$ & $\begin{array}{l}\text { Infants vaccinated } \\
\text { (MR1) }\end{array}$ & $\begin{array}{l}\text { Difference (Penta1- } \\
\text { MCV1) }\end{array}$ & $\begin{array}{l}\text { Dropout } \\
\text { rate }\end{array}$ & $\begin{array}{l}\text { Dropout } \\
\%\end{array}$ & $\begin{array}{l}P \\
\text { value }\end{array}$ \\
\hline 2004 & 2101 & 1754 & 347 & 0.165159 & 16.5 & $\begin{array}{l}< \\
0.001\end{array}$ \\
\hline 2010 & 3712 & 3531 & 181 & 0.048761 & 4.9 & $\begin{array}{l}< \\
0.001\end{array}$ \\
\hline $\begin{array}{l}2015- \\
16\end{array}$ & 3134 & 2933 & 201 & 0.064135 & 6.4 & $\begin{array}{l}< \\
0.001\end{array}$ \\
\hline
\end{tabular}

Effective Immunization Coverage

The Results of Effective Immunization Coverage showed a U-shaped pattern in all the indicators (initial utilization-Penta1, continuous utilization-Penta3, Adequate coverage-MCV1, and full vaccination coverage), Fig. 4. The coverage for Penta 1 was $95 \%$ in $2004,98 \%$ in $2010,97 \%$ and in $2015-16$. Whilst FVC was $65 \%$ in $2004,84 \%$ in 2010 and $73 \%$ in 2015-16.

Chi-Square results by geographical region

Table 4 shows the results of bivariate analysis of effective immunization coverage by geographical region. In 2004, significantly high coverage of Penta1 (97.22\%), Penta3 (89.68\%), MCV1 (83.33\%) and FVC (70.63) was observed in the northern region. In 2010, significantly high coverage of Penta1 (98.39\%), Penta3 (95.86\%), MCV1 (94.51\%) and FVC (85.58\%) was observed in the northern region. In 2015-16, significantly high coverage of Penta1 (98.16\%) and FVC (74.96\%) was observed in the northern region. 
Table 4

Bivariate analysis of the geographical region variation in effective immunization coverage.

\begin{tabular}{|c|c|c|c|c|c|c|c|c|c|}
\hline \multicolumn{4}{|c|}{2004} & \multicolumn{3}{|l|}{2010} & \multicolumn{3}{|l|}{ 2015-16 } \\
\hline Factor & No & Yes & & No & Yes & & No & Yes & \\
\hline & $n(\%)$ & $n(\%)$ & $\begin{array}{l}P \text { - } \\
\text { value }\end{array}$ & $n(\%)$ & $n(\%)$ & $\begin{array}{l}P \text { - } \\
\text { value }\end{array}$ & $n(\%)$ & $n(\%)$ & $\begin{array}{l}P \text { - } \\
\text { value }\end{array}$ \\
\hline \multicolumn{10}{|c|}{ Pentavalent1 } \\
\hline Region & & & $\begin{array}{l}< \\
0.0001\end{array}$ & & & 0.0017 & & & 0.0016 \\
\hline North & $\begin{array}{l}7 \\
(2.78)\end{array}$ & $\begin{array}{l}245 \\
(97.22)\end{array}$ & & $\begin{array}{l}14 \\
(2.06)\end{array}$ & $\begin{array}{l}667 \\
(97.94)\end{array}$ & & $\begin{array}{l}11 \\
(1.84)\end{array}$ & $\begin{array}{l}588 \\
(98.16)\end{array}$ & \\
\hline Central & $\begin{array}{l}68 \\
(8.05)\end{array}$ & $\begin{array}{l}777 \\
(91.59)\end{array}$ & & $\begin{array}{l}45 \\
(3.57)\end{array}$ & $\begin{array}{l}1217 \\
(96.43)\end{array}$ & & $\begin{array}{l}21 \\
(1.86)\end{array}$ & $\begin{array}{l}1111 \\
(98.14)\end{array}$ & \\
\hline Southern & $\begin{array}{l}35 \\
(3.14)\end{array}$ & $\begin{array}{l}1079 \\
(96.86)\end{array}$ & & $\begin{array}{l}30 \\
(1.61)\end{array}$ & $\begin{array}{l}1828 \\
(98.39)\end{array}$ & & $\begin{array}{l}59 \\
(3.95)\end{array}$ & $\begin{array}{l}1435 \\
(96.05)\end{array}$ & \\
\hline \multicolumn{10}{|c|}{ Pentavalent3 } \\
\hline Region & & & $\begin{array}{l}< \\
0.0001\end{array}$ & & & $\iota_{0.001}$ & & & 0.5618 \\
\hline North & $\begin{array}{l}26 \\
(10.32)\end{array}$ & $\begin{array}{l}226 \\
(89.68)\end{array}$ & & $\begin{array}{l}34 \\
(4.99)\end{array}$ & $\begin{array}{l}647 \\
(95.01)\end{array}$ & & $\begin{array}{l}38 \\
(6.34)\end{array}$ & $\begin{array}{l}561 \\
(93.66)\end{array}$ & \\
\hline Central & $\begin{array}{l}190 \\
(22.49)\end{array}$ & $\begin{array}{l}655 \\
(77.51)\end{array}$ & & $\begin{array}{l}105 \\
(8.32)\end{array}$ & $\begin{array}{l}1157 \\
(91.68)\end{array}$ & & $\begin{array}{l}79 \\
(83.08)\end{array}$ & $\begin{array}{l}1053 \\
(93.02)\end{array}$ & \\
\hline Southern & $\begin{array}{l}158 \\
(14.18)\end{array}$ & $\begin{array}{l}956 \\
(85.82)\end{array}$ & & $\begin{array}{l}17 \\
(4.14)\end{array}$ & $\begin{array}{l}1781 \\
(95.86)\end{array}$ & & $\begin{array}{l}114 \\
(83.08)\end{array}$ & $\begin{array}{l}1380 \\
(92.37)\end{array}$ & \\
\hline \multicolumn{10}{|l|}{ MCV1 } \\
\hline Religion & & & 0.0002 & & & $\dot{0}_{0.001}$ & & & 0.7056 \\
\hline North & $\begin{array}{l}42 \\
(16.67)\end{array}$ & $\begin{array}{l}210 \\
(83.33)\end{array}$ & & $\begin{array}{l}45 \\
(6.61)\end{array}$ & $\begin{array}{l}636 \\
(93.39)\end{array}$ & & $\begin{array}{l}56 \\
(9.35)\end{array}$ & $\begin{array}{l}543 \\
(90.65)\end{array}$ & \\
\hline Central & $\begin{array}{l}213 \\
(25.21)\end{array}$ & $\begin{array}{l}632 \\
(74.79)\end{array}$ & & $\begin{array}{l}123 \\
(9.75)\end{array}$ & $\begin{array}{l}1139 \\
(90.25)\end{array}$ & & $\begin{array}{l}96 \\
(8.48)\end{array}$ & $\begin{array}{l}1036 \\
(91.52)\end{array}$ & \\
\hline Southern & $\begin{array}{l}202 \\
(18.13)\end{array}$ & $\begin{array}{l}912 \\
(81.87)\end{array}$ & & $\begin{array}{l}102 \\
(5.49)\end{array}$ & $\begin{array}{l}1756 \\
(94.51)\end{array}$ & & $\begin{array}{l}140 \\
(9.37)\end{array}$ & $\begin{array}{l}1354 \\
(90.63)\end{array}$ & \\
\hline \multicolumn{10}{|l|}{ FVC } \\
\hline Religion & & & $\begin{array}{l}< \\
0.0001\end{array}$ & & & $<_{0.001}$ & & & 0.0002 \\
\hline North & $\begin{array}{l}74 \\
(29.37)\end{array}$ & $\begin{array}{l}178 \\
(70.63)\end{array}$ & & $\begin{array}{l}98 \\
(14.39)\end{array}$ & $\begin{array}{l}583 \\
(85.61)\end{array}$ & & $\begin{array}{l}150 \\
(25.04)\end{array}$ & $\begin{array}{l}449 \\
(74.96)\end{array}$ & \\
\hline
\end{tabular}




\begin{tabular}{|lllllll|}
\hline \multicolumn{3}{|c}{$\mathbf{2 0 0 4}$} & \multicolumn{5}{c|}{$\mathbf{2 0 1 0}$} & $\mathbf{2 0 1 5 - 1 6}$ \\
\hline Central & 348 & 497 & 262 & 1000 & 316 & 816 \\
& $(41.18)$ & $(58.82)$ & $(20.76)$ & $(79.24)$ & $(27.92)$ & $(72.08)$ \\
\hline Southern & 347 & 767 & 268 & 1590 & 418 & 1076 \\
& $(31.15)$ & $(68.85)$ & $(14.42)$ & $(85.58)$ & $(27.89)$ & $(72.02)$ \\
\hline \multicolumn{7}{|l}{ FVC, Full Vaccine Coverage, MCV1, Measles Containing Vaccine } \\
\hline
\end{tabular}

Logistic Regression Results

Tables 5 and 6 show the magnitude of being unimmunized with Penta3 and MCV1. In Table 5, compared to children who got immunized with Penta1, those with Penta3 were $74 \%$ (odds ratio [OR]: 0.26 ; $95 \%$ confidence interval [Cl]: 0.21-0.32) less likely to be immunized in 2004. Compared to children with Penta1 immunization, those children with Penta3 were 60\% less (OR: 0.40; 95\% Cl: 0.31-0.51) in 2010. Additionally, children in 201516 well $62 \%$ (OR: $0.29 ; 95 \%$ Cl: $0.23-0.48$ ) less likely to be immunized with Penta3, compared with Penta1. In Table 6, children were $81 \%$ less likely to be immunized with MCV1 (OR: 0.19; 95\% 0.16-0.24) in 2004 compared to children who got immunized with Penta1. In 2010, children were $69 \%$ (OR: $0.31 ; 95 \% \mathrm{Cl}: 0.25-0.40$ ) less likely to be immunized with MCV1 compared to Penta1. Further, in 2015-16 children were 71\% (OR: $0.29 ; 95 \% \mathrm{Cl}$ : 0.23-0.37) less likely to be immunized with MCV1 compared to those immunized with Penta1.

Table 5

Logistic Regression results for Penta

\begin{tabular}{|c|c|c|c|c|c|c|}
\hline & \multicolumn{2}{|c|}{$\begin{array}{l}\text { Infants vaccinated } \\
\text { (Penta1) }\end{array}$} & \multicolumn{2}{|c|}{$\begin{array}{l}\text { Infants vaccinated } \\
\text { (Penta3) }\end{array}$} & \multirow[t]{2}{*}{ Logistic Regression } & \multirow[t]{2}{*}{$P$-value } \\
\hline & No & Yes & No & Yes & & \\
\hline Year & $n(\%)$ & $n(\%)$ & $n(\%)$ & $n(\%)$ & OR 95\% Cl & \\
\hline 2004 & $110(4.98)$ & 2101 (95.02) & $374(16.92)$ & $1837(83.08)$ & $0.26(0.21-0.32)$ & $<0.001$ \\
\hline 2010 & $89(2.34)$ & $3712(97.66)$ & $216(5.68)$ & $3585(94.32)$ & $0.40(0.31-0.51)$ & $<0.001$ \\
\hline 2015-16 & $91(2.82)$ & 3134 (97.82) & $231(7.16)$ & 2994 (92.84) & $0.38(0.29-0.48)$ & $<0.001$ \\
\hline
\end{tabular}


Table 6

Logistic Regression results for MCV1

\begin{tabular}{|c|c|c|c|c|c|c|}
\hline & $\begin{array}{l}\text { Infants vac } \\
\text { (Penta1) }\end{array}$ & inated & $\begin{array}{l}\text { Infants vacci } \\
\text { (MCV1) }\end{array}$ & lated & Logistic Regression & $P$-value \\
\hline & No & Yes & No & Yes & & \\
\hline Year & $n(\%)$ & $n(\%)$ & $n(\%)$ & $n(\%)$ & OR 95\% Cl & \\
\hline 2004 & $110(4.98)$ & 2101 (95.02) & $475(20.67)$ & $1754(79.33)$ & $0.19(0.16-0.24)$ & $<0.001$ \\
\hline 2010 & $89(2.34)$ & $3712(97.66)$ & $270(7.10)$ & $3531(92.90)$ & $0.31(0.25-0.40)$ & $<0.001$ \\
\hline 2015-16 & $91(2.82)$ & 3134 (97.82) & $292(9.05)$ & $2933(90.95)$ & $0.29(0.23-0.37)$ & $<0.001$ \\
\hline
\end{tabular}

\section{Discussion}

Health inequities occur when health services are not accessible or utilized by certain people, based on socioeconomic and demographic characteristics. These inequities can result from a lack of resources required to meet the needs of vulnerable populations. Immunization is the process whereby an individual is made immune or resistant to an infectious disease, typically by the administration of a vaccine [30]. Immunization can be delivered successfully through outreach clinics and does not require any major lifestyle change. Hence, it is even accessible to the most hard-to-reach and vulnerable populations [30]. The overarching aim of the present study was to examine the effective immunization coverage, immunization dropout rate and equity gaps among children age 12-23 months in Malawi. The current study revealed that immunization coverage was above $90.0 \%$ in most of the antigens while the full immunization status was estimated at $65-73 \%$ between 2004 and 2015. The highest coverage was observed in BCG and lowest in Oral Polio Vaccine1 (OPV1). The bottleneck analysis revealed that initial utilization of immunization was high (Penta1 coverage) in all cohort years. As regards continuous utilization, the bottleneck analysis revealed that over the years the coverage of Penta3 has improved with over $90 \%$ coverage in 2010 and 2015. Similar patterns were observed in continued immunization services (MCV1).

The bottleneck analysis revealed that despite the high coverages of various antigens, however, the quality of immunization in Malawi (equity gaps) is lagging behind. This is reflected by the low prevalence of full vaccination coverage (FVC) across the years. This study revealed that across all the cohort years, children were less likely to be immunized with Penta3 and MCV1 which shows that a certain fraction of parents have difficulties in getting to (accessing) the immunization services for subsequent doses as well as parents are not utilizing the health services (underutilization of services). However, Penta1 coverage was high showing that an availability and initial utilization of immunization services is satisfactory in Malawi.

Dropout rate is assessed by the number of Penta1 and Penta3 or Penta1 and MCV1 that was given to the child over a year. According to the WHO, a dropout rate of greater than $10 \%$ is considered to be undesirable and its shows that a certain health facility has utilization constraints [31]. In this study, the dropout rates of Penta3 and MCV1 were significantly higher than 10\% in 2004 and lower than 10\% in 2010, and 2015-16. A low drop-out 
rates are indicative of good utilization and therefore of good service quality. Similarly, more children were unimmunized with Penta3 and MCV1 in 10\% in 2004. However, both dropout rates and unimmunized statues had U-shaped patterns indicating that immunization service in Malawi is deteriorating in the recent years. The possible causes of low immunization uptake or high dropout rates varies across the countries/regions, however, most countries in sub-Saharan Africa share similar root causes. The most common reasons for poor immunization are service organization problems, staffing problems, and data collection as well as reporting problems [32].

In line with previous research [8][14], the current study found that full immunization coverage were below the $90 \%$ of the national target set by the WHO. An analysis of the effects of individual and community level factors on childhood immunization in Malawi indicated that women's education especially those with no formal education, women with either one antenatal visit or none, women who had no immunization card/no longer have an immunization card, women from the poorest households, women with three and more children, women from central region, and women from the communities who perceived distance to the nearest health facility were reported to have reduced odds of achieving full immunization coverage [8][14]. In Mozambique it was reported that accessibility to the vaccination sites, no schooling of mothers and children born at home or outside were the reasons for incomplete vaccination [33]. Additionally, being born at health institutions, higher level of maternal education, media exposure, region of residence and residing in communities possessing higher maternal antenatal care services utilization were positively associated with childhood full immunization In Ethiopia [34].

\section{Recommendations}

There is need for intensified sensitizations, engagement with communities through REC approach so that children are fully immunized. There is a need for health education and orientation of service providers. In addition, immunization registers and data quality should be looked into and dealt with accordingly. Further research at health facility levels is needed to valid the results of the current study and also to establish health facilities that are underperforming.

\section{Conclusion}

Childhood full immunized status over the 15 years has been lagging behind and immunization coverages for most of antigens are high while dropout rate over the last 10 years is lower than the recommended cutoff point by WHO. Furthermore, initial utilization of immunization services was satisfactory whilst continued utilization and adequate coverage of immunization services had irregular patterns. These results might be of great essence to the Malawi EPI in an effort to address disparities that are occurring in immunization services.

\section{Abbreviations}

BCG, Bacillus Calmette-Guérin; CHAM, Christian Association of Malawi; Cl, Confidence Interval; DHS, Demographic Health Survey; DPT, Diphtheria-Tetanus-Pertussis; EPI, Expanded Programme on Immunization; FIC, Fully immunized coverage; FVC, Full Vaccination Coverage; GDP, Gross Domestic Product; GVAP, Global Vaccine Action Plan; HepB, Hepatitis B; Hib, Haemophilus influenza type b; HPV, Human Papilloma Vaccine; ICF; International Classification Function; MCV, Measles Containing Vaccine; MDHS, Malawi Demographic and 
Health Survey; MoH, Ministry of Health; NGOs, Non-government Organization; NHSRC, National Health Sciences Research Committee; NSO, National Statistical Office; OR, Odds Ratio; OVP, Oral Polio Vaccine; PCV, Pneumococcal Conjugate Vaccine; RV, Rotavirus Vaccine; TAs, Traditional Authorities; TB, Tuberculosis; TT, Tetanus Toxoid; WHO, World Health Organization; WRA, Women of Reproductive Age; UNICEF, United Nations Children Fund; NSO, National Statistics Office.

\section{Declarations}

Ethics approval and consent to participate

This study was conducted according to the guidelines laid down in the Declaration of Helsinki and all procedures involving human subjects were approved by the Malawi National Health Science Research Committee and the Institutional Review Board (IRB) of ICF Macro, and the Centers for Disease Control (CDC) in Atlanta. Informed consent was obtained at the beginning of each interview and the authors sought permission from the DHS program for the use of the data. The data obtained from respondents were anonymous as names not written down thus ethics approval for this study was not required.

Consent for publication

Not applicable

Availability of data and material

The datasets generated and/or analyzed during the current study are available in the DHS Program repository, https://dhsprogram.com/data/dataset/Malawi_Standard-DHS_2015.cfm?flag=1.

Competing interests

The authors declare no conflict of interest

Funding

This research did not receive a grant from any funding agency in the public, commercial, or not-for-profit sectors. The funding for the 2015-16 MDHS was provided by the government of Malawi, the United States Agency for International Development (USAID), the United Nations Children's Fund (UNICEF), the Malawi National AIDS Commission (NAC), the United Nations Population Fund (UNFPA), UN WOMEN, Irish Aid, and the World Bank.

Authors' Contributions

ON, ETM, and KM contributed to the conception and design of the study. PAMN acquired data, conducted analysis, FNT interpreted results. PAMN, KM, and FNT drafted the first article. ON and ETM revised the draft critically for important intellectual content. All authors reviewed and approved the final version of the manuscript.

Acknowledgements

Page 14/19 
The authors are sincerely grateful to National Statistical Office (NSO) of Malawi for data collection. We give thanks to the MEASURE DHS for providing us with the population-based dataset through their archives which can be downloaded from http://dhsprogram.com/data/available-datasets.cfm.

\section{References}

1. Rodrigues CMC, Plotkin SA. Impact of Vaccines; Health, Economic and Social Perspectives. Front Microbiol 2020. doi:10.3389/fmicb.2020.01526.

2. World Health Organization (WHO). Vaccines and immunization. WHO Geneva Switz 2021. https://www.who.int/health-topics/vaccines-and-immunization\#tab=tab_1 (accessed January 24, 2021).

3. World Health Organization (WHO). The Expanded Programme on Immunization. Geneva, Switz 2016. http://www.who.int/immunization/programmes_systems/supply_chain/benefits_of_immunization/en/ (accessed December 30, 2016).

4. Centers for Disease Control and Prevention (CDC). New and Underused Vaccines. CDC US Dep Heal Hum Serv 2017. https://www.cdc.gov/globalhealth/immunization/sis/vacs_detail.htm (accessed January 24, 2021).

5. World Health Organization (WHO). Immunization coverage. Geneva, Switz 2018. https://www.who.int/news-room/fact-sheets/detail/immunization-coverage (accessed December 27, 2018).

6. World Health Organization (WHO). Immunization Today and in the next Decade. 2018.

7. Malawi Ministry of Health $(\mathrm{MoH})$. Expanded Programme on Immunization. $\mathrm{MoH} 2016$. http://www.health.gov.mw/index.php/expanded-programme-on-immunization (accessed December 21, 2017).

8. Munthali AC. Determinants of vaccination coverage in Malawi: evidence from the demographic and health surveys. Malawi Med J 2007;19:79-82. doi:10.4314/mmj.v19i2.10934.

9. National Statistical Office N, ICF Macro. Malawi Demographic and Health Survey 2010. Zomba, Malawi, and Calverton, Maryland, USA: NSO and ICF Macro. Malawi: 2011.

10. National Statistical Office (NSO) [Malawi] and ICF. Malawi Demographic and Health Survey 2015-16. Zomba, Malawi, and Rockville, Maryland, USA. NSO and ICF. 2017.

11. Governrnment of Malawi (GoM). EPI Comprehensive Multi-Year Plan Malawi September. 2016.

12. World Health Organization (WHO), Observatory African Health. Malawi - Analytical summary Immunization and vaccines development. WHO Geneva Switz 2018.

http://www.aho.afro.who.int/profiles_information/index.php/Malawi:Analytical_summary__Immunization_and_vaccines_development (accessed July 8, 2018).

13. Yawson AE, Bonsu G, Senaya LK, Yawson AO, Eleeza JB, Banskota HK. Regional disparities in immunization services in Ghana through a bottleneck analysis approach: implications for sustaining national gains in immunization. Arch Public Heal 2017:1-10. doi:10.1186/s13690-017-0179-7.

14. Ntenda PAM, Chuang K-Y, Tiruneh FN, Chuang Y-C. Analysis of the effects of individual and community level factors on childhood immunization in Malawi. Vaccine 2017;35:1907-1917. doi:10.1016/j.vaccine.2017.02.036. 
15. Tsega A, Hausi H, Chriwa G, Steinglass R, Smith D, Valle M. Vaccination coverage and timely vaccination with valid doses in Malawi. Vaccine Reports 2016. doi:10.1016/j.vacrep.2016.06.001.

16. Wetherill O, Lee C, Dietz V, Wetherill O, C-w L, Root D V, et al. Root Causes of Poor Immunisation Data Quality and Proven Interventions: A Systematic Literature Review 2017;2:1-7.

17. Mane AB. Immunization dropout rates: some issues. Ann Med Health Sci Res 2015;5:153. doi:10.4103/2141-9248.153639.

18. The Malawi Project. Geography 2018. https://www.malawiproject.org/zzz/geography/ (accessed December 27, 2018).

19. National Statistical Office (NSO) [Malawi]. Malawi in Figures 2016. Zomba: 2016.

20. National Statistical Office (NSO), ICF Macro. Malawi Demographic and Health Survey 2010. Zomba, Malawi, and Calverton, Maryland, USA: NSO and ICF Macro. 2011.

21. The World Bank (WB). Malawi. World Bank Group/E Libr 2018. https://data.worldbank.org/country/malawi (accessed December 27, 2018).

22. Governrnment of Malawi (GoM). Malawi Growth and Development Strategy II 2011-2016 2010.

23. Makwero MT. Delivery of primary health care in Malawi. African J Prim Heal Care Fam Med 2018;10. doi:10.4102/phcfm.v10i1.1799.

24. National Statistical Office (NSO), ICF Macro. Malawi Demographic and Health Survey 2010. Zomba, Malawi, and Calverton, Maryland, USA: NSO and ICF Macro. 2011.

25. National Statistical Office (NSO) [Malawi], ORC Macro. Malawi Demographic and Health Survey 2004. Calverton, Maryland: NSO and ORC Macro. 2005.

26. Njiraini R, Agongo E, Awoonor-Williams J, Selenje L, Banskota H, Ngongalah V, et al. Adoption and use of the bottleneck analysis approach in Ghana 's health sector 2015:46.

27. UNICEF. Enhanced Programming and Results through Monitoring Results for Equity Systems (MoRES) 2013;1:3.

28. Health Education and Training (HEAT). Immunization Module: Monitoring your Immunization Programme n.d. http://www.open.edu/openlearncreate/mod/oucontent/view.php? id=53371\&section=1.4.2 (accessed January 20, 2019).

29. Chinawa J. Immunization dropout rates in ihe, awgu local government area, enugu state, South East Nigeria: a 1 year review. Ann Med Heal Sci Res 2014;4:642-6. doi:10.4103/2141-9248.139360.

30. World Health Organization (WHO). Immunization. Geneva, Switz 2018.

https://www.who.int/topics/immunization/en/ (accessed December 24, 2018).

31. World Health Organization (WHO). The EPI Coverage Survey. Training for Mid-level Managers. 2008.

32. Immunization Module. Monitoring your Immunization Programme n.d.

http://www.open.edu/openlearncreate/mod/oucontent/view.php?id=53371\&printable=1 (accessed February 22, 2019).

33. Jani J V, De Schacht C, Jani I V, Bjune G. Risk factors for incomplete vaccination and missed opportunity for immunization in rural Mozambique. BMC Public Health 2008;8:161. doi:10.1186/1471-2458-8-161.

34. Abadura SA, Lerebo WT, Kulkarni U, Mekonnen ZA. Individual and community level determinants of childhood full immunization in Ethiopia: a multilevel analysis. BMC Public Health 2015;15:972. 


\section{Figures}

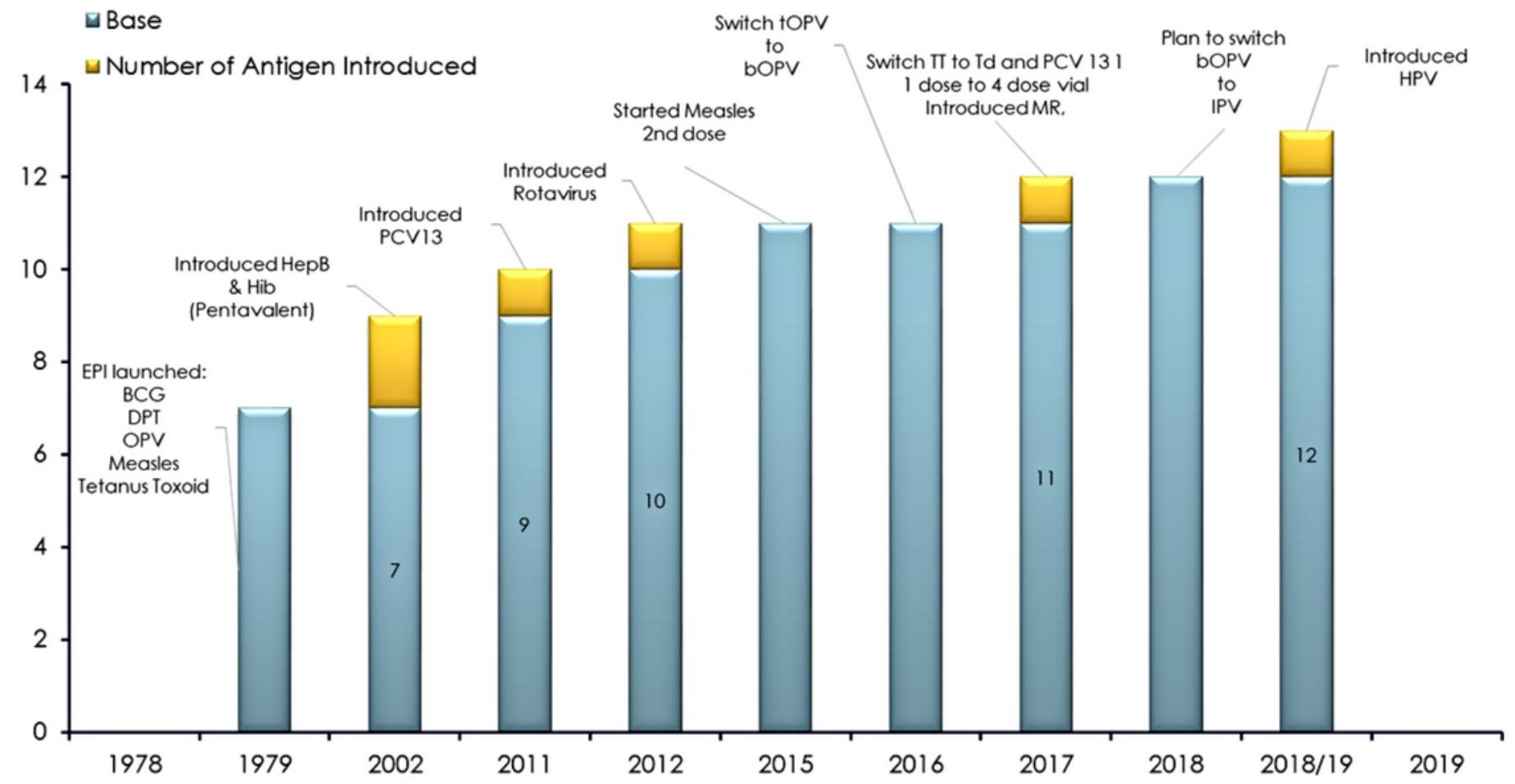

Figure 1

Number of antigens introduced in EPI schedule since 1979 


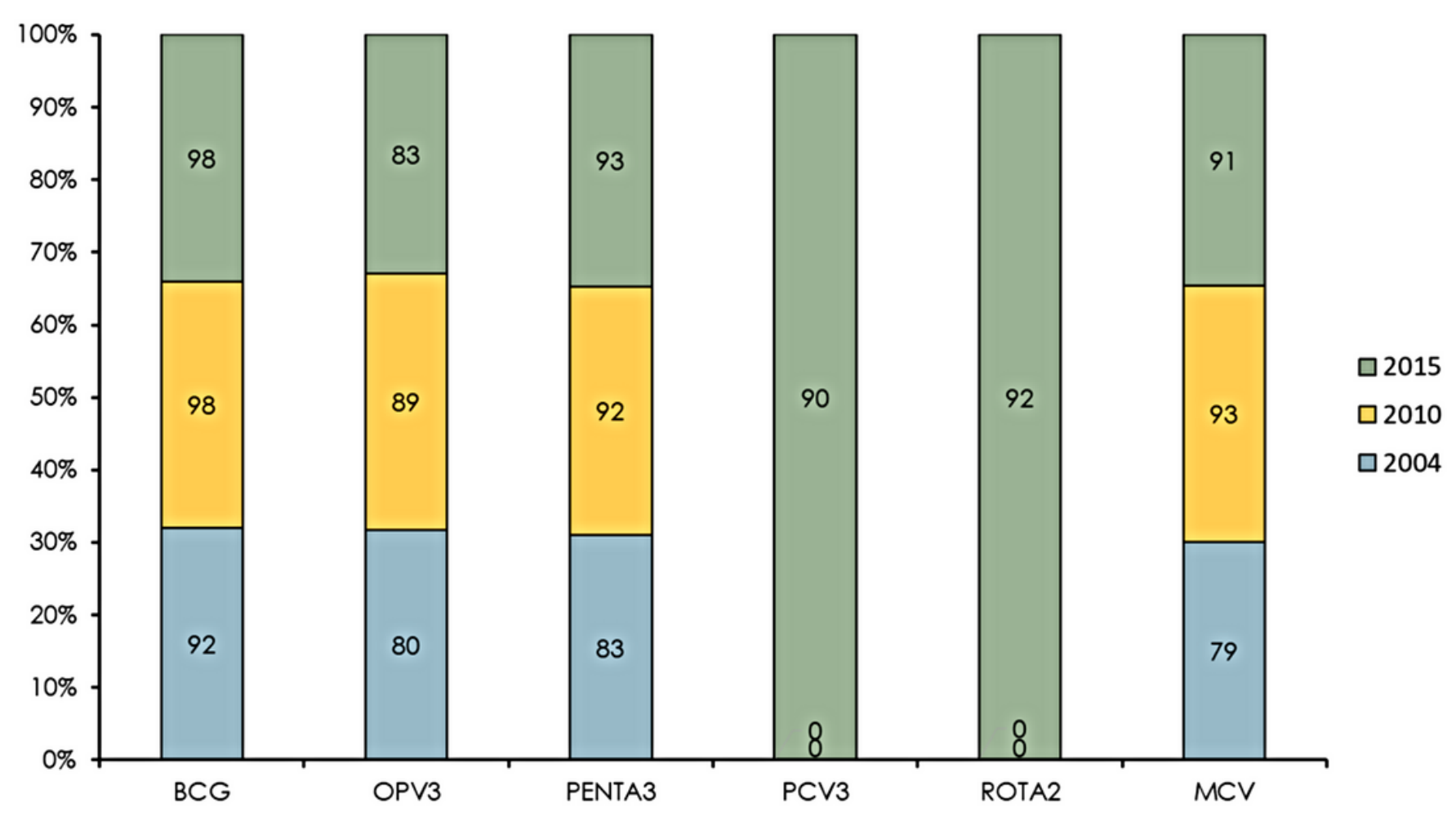

Figure 2

Trends in immunization coverage 2004-2015-16

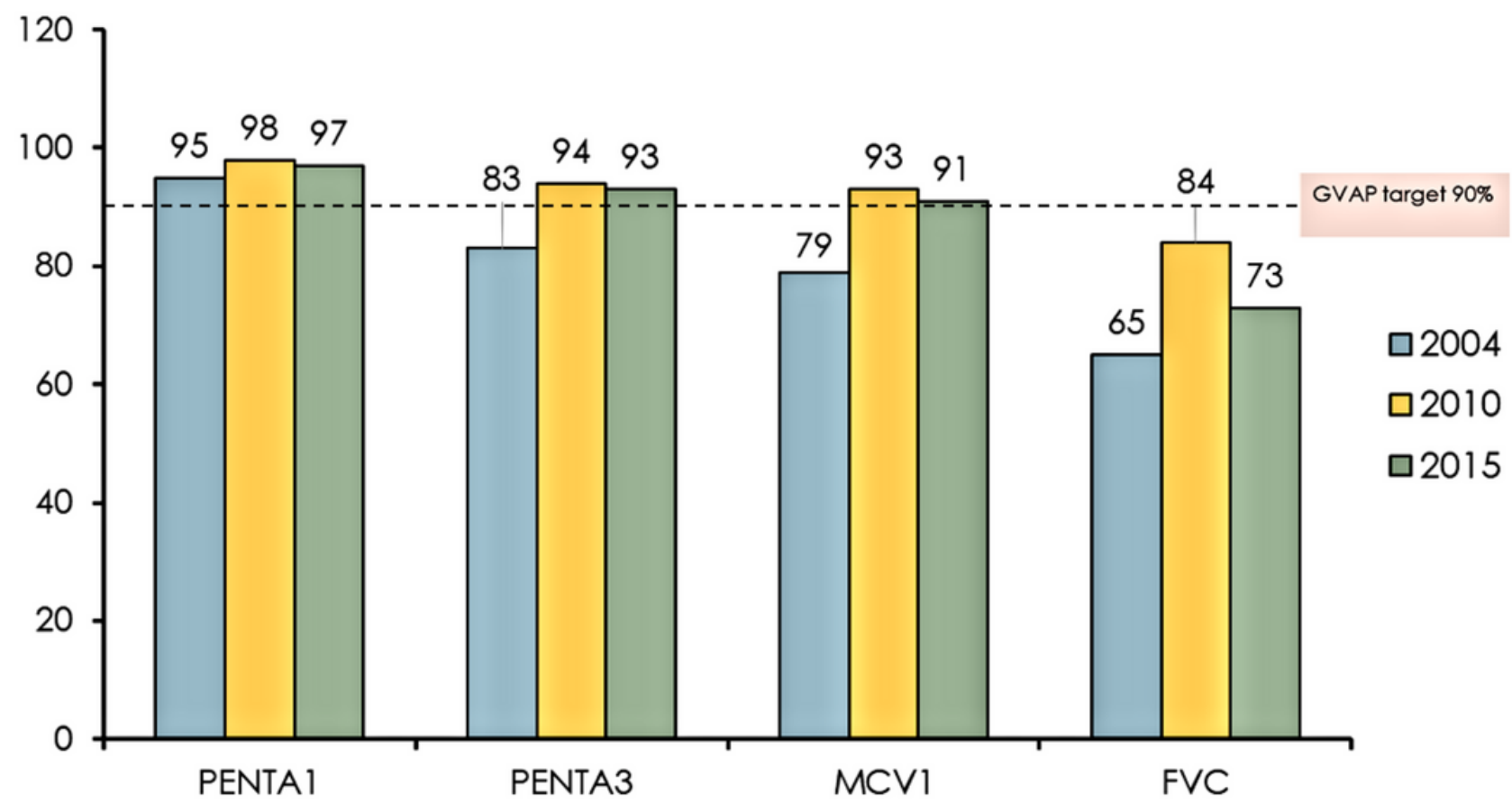

Figure 3 
Unvaccinated children with Penta 3 and MCV1

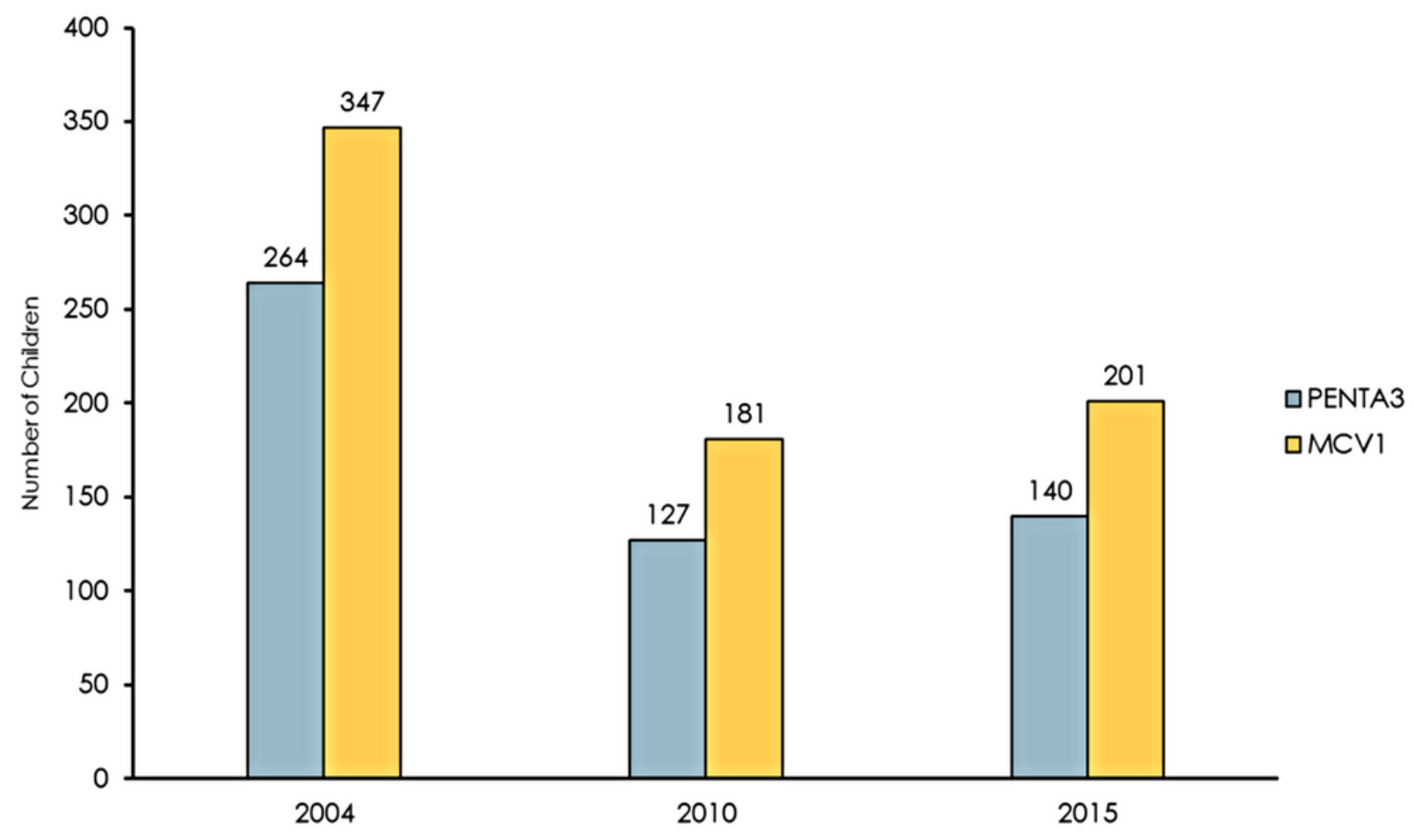

Figure 4

Bottlenecks in the delivery of immunization services 